TRANS · núm. 25.2021

MISCELÁNEA · 373-394

AUDIOVISUAL

Este artículo explora y describe el estado actual de la industria audiovisual francófona en España, así como el perfil socioprofesional y las principales características de la profesión del traductor audiovisual con francés como lengua origen: volumen de encargos, modalidades más demandadas, principales clientes, canales de distribución, etc. Para ello, hemos realizado, por un lado, una revisión de informes proporcionados por instituciones nacionales e internacionales sobre la industria audiovisual francófona, y por otro, hemos empleado un cuestionario al que respondieron 69 traductores especialistas en francés como lengua origen. Entre otros, los resultados muestran un volumen de importación de productos francófonos - con el cine galo como máximo exponente- bastante reducido. Así, estos encargos son relativamente escasos y parecen distribuirse de modo desigual entre los profesionales. Asimismo, la omnipresencia del inglés en lo audiovisual es evidente, pues un elevado porcentaje de los profesionales especializados en francés también ofrece servicios en inglés.

PALABRAS CLAVE: traducción audiovisual, francés, perfil socioprofesional, industria, profesión.

\title{
La traducción audiovisual desde el francés en España: aproximación a la industria y la profesión
}

\author{
Beatriz Reverter Oliver \\ José Fernando Carrero Martín \\ Universitat de València
}

\section{Audiovisual Translation from French in Spain: an approach to the industry and the profession}

This article explores and describes the current state of the French-speaking audiovisual industry in Spain, as well as the socio-professional profile and the main characteristics of the audiovisual translation profession with French as a source language: volume of assignments, most demanded modalities, main clients, distribution channels, etc. To this end, we have carried out, on the one hand, a review of reports provided by national and international institutions on the French-speaking audiovisual industry, and on the other hand, we have used a questionnaire answered by 69 translators specialising in French as a source language. Among other things, the results show that the volume of imports of French-language products -with French cinema as the main exponent-is quite low. Thus, these assignments are relatively rare and appear to be unevenly distributed among professionals. Moreover, the omnipresence of English in the audiovisual field is evident, as a high percentage of professionals specialising in French also offer services in English.

KEY WORDS: audiovisual translation, French, socio-professional profile, industry, profession. 


\section{1. INTRODUCCIÓN}

A lo largo de las últimas dos décadas, la producción de contenidos audiovisuales ha experimentado un enorme crecimiento gracias a la llegada de la Televisión Digital Terrestre (TDT) en la década de los 2000 - que trajo consigo una amplia variedad de canales a las televisiones en abierto-y a la proliferación de los servicios de video bajo demanda (VOD) en la de 2010 - con plataformas como Netflix, HBO Max, Amazon Prime o Disney +, entre otras, alcanzando más de 100 millones de suscriptores en Europa (Observatorio Audiovisual Europeo, 2020)-. A esto no solo se suman también los canales de distribución y exhibición tradicionales, como pudieran ser el cine o la televisión de pago, sino también otros materiales, como contenidos audiovisuales promocionales o de consumo interno que pueden venir de una amplia variedad de sectores empresariales (Reverter Oliver et al., 2021). Todo ello ha tenido un efecto directo en la traducción audiovisual (TAV), que en los últimos 20 años ha experimentado un enorme crecimiento, no solo desde una perspectiva profesional - tanto en sus modalidades tradicionales, como doblaje, subtitulado o voces superpuestas; como en otras como la localización de videojuegos, dado el notable crecimiento de esta industria durante los últimos 20 años, o las correspondientes a la accesibilidad audiovisual como consecuencia de regulaciones introducidas por la Unión Europea (UE) en la materia-, sino también desde un punto de vista docente y académico (Carrero Martín et al., 2019).

No obstante, a este auge de los contenidos audiovisuales y su traducción conviene sumarle otro hecho: el aumento de la producción audiovisual europea. Y es que, en el 2018, la UE publicó la Directiva (UE) 2018/1808 (2018: en línea), según la cual se establecía que: [1]os Estados miembros velarán por que los prestadores de servicios de comunicación audiovisual a petición sujetos a su jurisdicción dispongan de un porcentaje de al menos el $30 \%$ de obras europeas en sus catálogos y garanticen la prominencia de dichas obras.

Esta directiva, sin embargo, no afecta solo a las televisiones, sino también a las plataformas de VOD, a las que los estados de la UE también pueden exigir contribuir a la producción audiovisual de cada país (Aguado-Guadalupe y Bernaola, 2019). En consecuencia, creemos que este escenario podría traducirse en un mayor número de lenguas origen de los productos audiovisuales, lo que podría suponer un aumento del volumen de trabajo para los traductores. Con todo, estos supuestos han de ser confirmados mediante futuras investigaciones.

Así pues, el objetivo del presente artículo es explorar y describir el estado actual en el que se encuentra la industria de la producción audiovisual francófona y su importación a España, así como algunas de las principales características del perfil del traductor y la profesión de la TAV con el francés como lengua origen (LO) - que, de acuerdo con el análisis del sector de la traducción en España elaborado por Rico Pérez y García Aragón (2016), es la segunda lengua de trabajo más extendida entre los traductores solo por detrás del inglés-. Este objetivo, a su vez, se divide en tres objetivos secundarios. En primer lugar, llevar a cabo una revisión general del estado de la distribución de productos audiovisuales francófonos en nuestro país; en segundo, realizar un estudio empírico mediante encuestas a profesionales de la TAV especialistas en francés con el fin de recabar datos sobre su perfil socioprofesional, y, en tercer lugar, observar las principales características que han presentado los encargos de TAV desde el francés en los últimos cinco años. 


\section{LA PRODUCCIÓN AUDIOVISUAL FRAN- CÓFONA: VOLUMEN Y DISTRIBUCIÓN EN ESPAÑA}

De acuerdo con la Organización Internacional de la Francofonía (OIF) (2019), el francés es la lengua oficial de 32 estados y gobiernos de todo el mundo - así como de una amplia variedad de organismos internacionales-y cuenta con cerca de 300 millones de hablantes nativos - y más de 50 millones no nativos - repartidos entre los cinco continentes. Esto la convierte en la quinta lengua más hablada del mundo, presente en países como Francia, Bélgica, Mónaco, Suiza, Canadá, Haití, República Democrática del Congo, etc.

No obstante, a pesar del importante papel del francés en el mundo, no somos conocedores de la existencia de estudios sobre la distribución del cine francófono en España, dado que únicamente contamos con datos que se limitan a informes elaborados por los diferentes países que componen la comunidad francófona - algunos de ellos sin ofrecer apenas información sobre exportación-, a estadísticas oficiales de nuestro país o a informes comerciales realizados por entidades como el Observatorio Audiovisual Europeo. Así pues, en el presente punto, esclareceremos cuál es esta situación, tratando de ofrecer una visión general de la posición del francés, no ya solo en el cine comercial de España, sino también en los servicios de VOD, festivales de cine, y más.

Como decimos, debido al elevado número de países de habla francesa, realizar un seguimiento exhaustivo de todas las producciones de origen francófono - no ya solo estrenos de contenido audiovisual en cadenas de cine comercial y festivales o distribuido para el mercado doméstico, sino también en cadenas de televisión públicas y privadas, tanto autonómicas como nacionales, o plataformas de VOD - es una tarea compleja. Aun así, Francia parece ser el país que ofrece la mayor cantidad de información en términos de distribución de productos audiovisuales. Según el Observatorio Audiovisual Europeo (2020: 12), Francia es el tercer miembro de la UE en términos de producción televisiva. No obstante, estos datos se tomaron cuando Reino Unido aún formaba parte de la UE, por lo que futuros estudios probablemente sitúen al país galo entre el primero o segundo productor de contenido televisivo de la Unión.

En lo que respecta al VOD en la UE, Francia aparece como el primer productor de series de televisión y películas, con un $28 \%$. Además, dentro de los servicios de VOD transaccionales - aquellos en los que hay que pagar para acceder a una obra determinada-, este país es el máximo exportador de películas y el segundo de series. Por otro lado, también es el máximo exportador de películas y series en los servicios de VOD por suscripción - aquellos en los que se paga una cuota mensual- (Grece y Jiménez Pumares, 2020) ${ }^{1}$.

Ya centrándonos en el estado de la distribución cinematográfica gala en España, el Ministerio de Cultura y Deporte señala que el cine francés tuvo en el año 2019 un total de 3,1 millones de espectadores ( $3 \%$ del público total) y recaudó 18,1 millones de euros (2,9\% del total), siendo el tercer país de la UE del que más se consume cine en España, por detrás de Alemania y Reino Unido (Ministerio de Cultura y Deporte, 2020). Por otro lado, de acuerdo con Unifrance - la organización responsable de la promoción del cine francés en el extranjero-, en los años 2015, 2016, 2017, 2018 y 2019, las películas francesas supusieron un $3,8 \%$, un $2,3 \%$, un $4,3 \%$, un $3 \%$ y un 3,4\% del mercado cinematográfico español, respectivamente. Así, en el año 2019 nuestro país fue el tercer mayor importador de

I Estos datos se tomaron una vez confirmada la salida del Reino Unido de la Unión Europea. 
376 cine francés, solo por detrás de Alemania e Italia En total, en ese año - el anterior a la crisis de la COVID-19- se estrenaron un total de 159 películas mayoritarias en lengua francesa - traídas por 29 distribuidores- En cuanto a producciones independientes en lengua francesa, se estrenaron 10. El género más visto fue la comedia y el menos visto, el documental (2020).

Sobre el estado del cine galo en las plataformas de VOD por suscripción en España, Unifrance (2020) indica que estas producciones suponían el 3,5\% del contenido en 2019, con Amazon Prime y Now TV como principales plataformas (5,3 $\%$ del contenido en ambas), seguidas por Movis$\operatorname{tar}+(4,2 \%)$. Por otro lado, el directorio de obras audiovisuales europeas en plataformas de VOD, el Lumiere VOD, indica que actualmente las plataformas españolas ofrecen un total de 3147 producciones galas, entre las que diferencia 2926 películas y 211 contenidos televisivos (Observatorio Audiovisual Europeo, s.f.). Sin embargo, este buscador no diferencia entre producciones y coproducciones ni tampoco indica el idioma original del contenido.

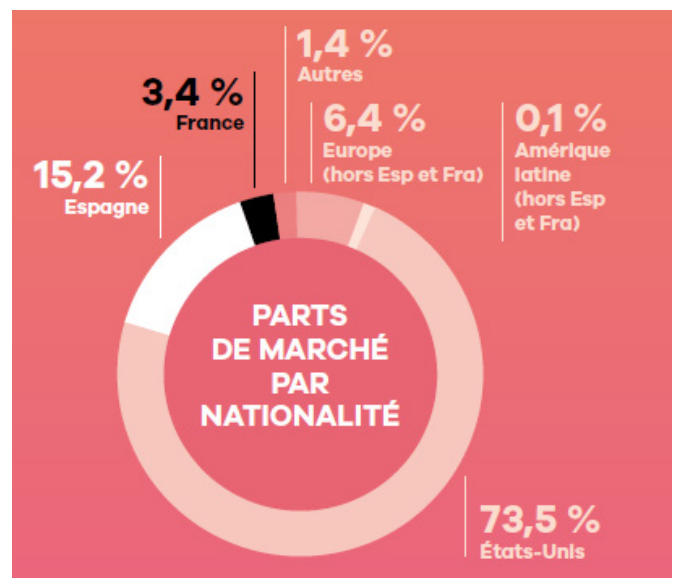

Además, Unifrance también recoge el estado del cine francés en un total de 10 festivales de cine de todo el mundo, uno de ellos siendo el Festival de Cine de San Sebastián, en el que en 2019 se proyectaron 34 películas francesas. Asimismo, señala que estas películas han supuesto un promedio de $25,8 \%$ del total de las proyectadas en este festival durante los últimos 10 años. Sobre los cortometrajes franceses, España ocupa el tercer puesto en consumo por detrás de EE. UU. y Reino Unido (2020).

Centrándonos ya en la producción de otros países francófonos, conviene resaltar que no parece existir excesiva documentación al respecto. En Europa, Bélgica parece ser el segundo país detrás de Francia en términos de producción. De acuerdo con Grece y Jiménez Pumares (2020), la producción belga en VOD supone un $3 \%$ del total de los productos audiovisuales de la UE. Según el ya mencionado directorio Lumiere VOD, actualmente España tiene acceso a 500 obras audiovisuales belgas — de las cuales 474 son películas y 26 , contenido televisivoDetrás encontramos la producción suiza, con

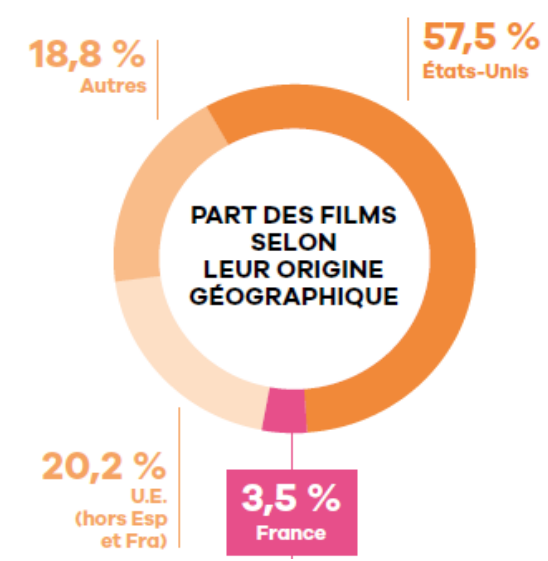

IMÁGENES I Y 2. Porcentaje de mercado del cine francés en las salas de cine y porcentaje de películas francesas disponibles en plataformas en España en 2019 (Unifrance, 2020:154,161) 
271 obras disponibles en España - 268 películas y 3 programas televisivos-, seguida por la de Luxemburgo con 71 — todas ellas películas-y, finalmente, la de Mónaco, con ocho - de nuevo, todas películas-. Pese a ello, tal y como hemos señalado con anterioridad, este directorio no diferencia entre los idiomas de la producción ni entre si hablamos de producciones de un solo país o coproducciones, por lo que existe la posibilidad de que la lengua de estas — sobre todo en países como Bélgica o Suiza - no sea necesariamente el francés (Observatorio Audiovisual Europeo, s.f.).

Fuera de Europa, en Canadá, la producción en lengua francesa — tanto televisión, como películas y contenido de VOD_ creció en el año 2019 un $13,6 \%$. Sin embargo, el valor de la misma -843 millones de dólares - se sitúa muy lejos de la producción inglesa $-2,35$ mil millones de dólares- (Canadian Media Producers Association Department of Canadian Heritage et al., 2020). En lo que respecta a la llegada de producción canadiense a España, de acuerdo con un informe de 2017, entre los años 2005 y 2013, nuestro país se encontraba entre los 10 principales compradores de películas canadienses, aunque no se indica la lengua de estas. No obstante, este informe sí señala que el inglés era el principal idioma de las películas exportadas, y que los principales compradores de películas de lengua francesa fueron Francia, Bélgica y Suiza (De Rosa y Burguess, 2017). En cuanto al cine francoafricano en España, apenas se tienen datos. De hecho, de acuerdo con el Ministerio de Cultura y Deporte (2020), el total del cine africano no sumó ninguna cifra en el mercado cinematográfico español en el año 2019.

Con todo, a la hora de hablar de contenido francófono traducido para España, destaca el canal de televisión TV5Monde. Disponible desde hace más de 20 años en nuestro país, este ofrece una amplia variedad de producciones audiovisuales francófonas — desde informati- vos a series de televisión pasando por películas, documentales, magazines culturales y más- de Francia, Bélgica, Suiza, Canadá, Mónaco y de los países francófonos africanos (TV5MondeEurope, 2019). Ya en el 2012, el canal estaba presente en el $96 \%$ de hogares españoles con canal por cable o satélite (s.a., 2012) y subtitulaba prácticamente todo su contenido a excepción de aquel en directo (F.M.B., 2012). Igualmente, a finales del año 2020, esta cadena estrenó su propia plataforma de VOD gratuita, con subtítulos en cinco idiomas, incluido el español: TV5Monde Plus. El catálogo de esta plataforma, al igual que el del canal, se compone de producciones francesas, belgas, suizas y africanas. En palabras del director general de TV5Monde, Yves Bigot (2020: 5):

[s] u catálogo está constituido por lo mejor y lo más duradero de los programas de nuestros canales asociados (France Télévisions, Radio-Canada, Télé-Québec, TV5 QuébecCanada, RTS, RTBF), por las producciones propias de TV5MONDE (magacines de información y culturales, documentales) y nuestras coproducciones en África (cine, series, documentales, programas infantiles, conciertos), así como también podcasts (balados, como los llaman los quebequenses), compras de películas de cine, ficciones, documentales y de animación provenientes de toda la Francofonía.

En total, la plataforma ofrece actualmente 2500 horas de contenido francófono, pero con vistas a llegar hasta las 5000. Además, se renuevan 150 horas de contenido de la plataforma cada mes (s.a., 2020). Así pues, tanto el canal como la plataforma suponen un enorme repertorio de obras audiovisuales venidas de una amplia variedad de países de origen francófono, las cuales se ofrecen traducidas al español mediante la modalidad de subtitulación.

Al margen, no podemos ignorar tampoco el contenido francófono emitido por parte de los 
378 canales de televisión (tanto públicos como privados) españoles, como pueden ser series, películas, programas de telerrealidad, etc. Aquí hay que tener en cuenta, además, el hecho de que existen cadenas públicas autonómicas que, a la hora de emitir contenido en francés, necesitan traducirlo a la lengua cooficial de su comunidad autónoma - ya sea mediante subtítulos o doblaje- . Por último, convendría señalar que el cine francófono tiene también presencia en nuestro país a través de los festivales de cine, con algunos centrados especialmente en la proyección de películas francófonas, como el Ohlalà! - Festival de cinema francòfon de Barcelona, el Festival de cine francés de Málaga, el Festival de cine canadiense de Madrid o el MyFrenchFilmFestival.com, un festival de cine en línea que ofrece su contenido subtitulado al español.

Una vez analizados los datos sobre la distribución de contenido audiovisual francófono en España, pasaremos a exponer los resultados del cuestionario, el cual nos ha permitido, gracias a las respuestas de un grupo de traductores audiovisuales especialistas en francés cuyas traducciones están destinadas al público español, comprender en mayor medida cuál parece ser el perfil socioprofesional más frecuente, así como qué características presentan con mayor asiduidad los encargos de traducción de contenido audiovisual francófono en los últimos cinco años.

\section{METODOLOGÍA}

\subsection{Paradigma del estudio}

Como mencionábamos anteriormente, no tenemos constancia de la existencia de estudios actualizados en España que recojan las características de la industria audiovisual francófona, así como tampoco del perfil socioprofesional de los traductores de estas obras ni de las características de su profesión; a saber, tarifas, flujo de trabajo, tipo de clientes, etc. Por ello, siguiendo a Hernández Sampieri et al. (2010), este sería un estudio con un alcance eminentemente exploratorio y descriptivo, de naturaleza cuantitativa, no experimental y transeccional, donde nuestra intención no es otra que tener una primera toma de contacto con la cuestión investigada, de modo que nos permita dibujar un escenario a partir del cual profundizar en el futuro para obtener datos más precisos.

Asimismo, este es un estudio de caso, donde la información se ha recogido mediante una encuesta. Por lo tanto, nuestro propósito no es generalizar los datos aquí obtenidos al total de la población — pues, como seguidamente se verá, al desconocer el número exacto del que esta se compone, no nos es posible valorar la idoneidad del número de respuestas obtenidas en términos de representatividad-, sino centrarnos en un número relativamente acotado de respuestas para estudiar la cuestión descrita mediante unas pocas unidades de individuos, aun tratando de obtener la máxima diversidad dentro de los respondientes (Monje Álvarez, 2011).

\subsection{Población del estudio}

La población del estudio se ha compuesto de traductores que ofrecen $-o$ han ofrecido a lo largo de su carrera profesional- servicios de TAV con francés como LO a cualquiera de las cuatro lenguas orales del territorio español: español, catalán (incluidas las variantes valenciana y balear) ${ }^{2}$, euskera y gallego. Para formar parte de la pobla-

2 De ahora en adelante, cuando hablemos de catalán, entiéndase que lo hacemos a cualquiera de sus variantes territoriales. 
ción no era excluyente, sin embargo, que un profesional no estuviese trabajando en un encargo desde el francés en el momento de responder al cuestionario, pues la fecha de los últimos encargos de aquellos que llevan años sin trabajar desde esta lengua también era información de interés.

Por lo tanto, los únicos criterios de inclusión de la población fueron: (1) ofrecer o haber ofrecido servicios como traductor audiovisual desde el francés y (2) traducir hacia, al menos, una de las lenguas orales del territorio español. Como adelantábamos, nuestra intención es recabar la máxima diversidad de respuestas de aquellos profesionales que cumplieran estos criterios con el fin de poder ofrecer una fotografía lo más completa y detallada posible. Esta decisión metodológica se tomó debido a que, pese a nuestros esfuerzos - por ejemplo, tras consultar la base de datos de la Asociación de Traducción y Adaptación Audiovisual Española (ATRAE), donde se recogen las combinaciones lingüísticas en las que ofrecen los servicios de traducción sus miembros-, no nos fue posible disponer de datos fiables sobre el número exacto de profesionales de los que se compondría la población. En consecuencia, no se siguió ninguna técnica de muestreo, sino que se trató de contactar con todas aquellas personas que cumplieran los criterios de inclusión de la población, mediante asociaciones profesionales como ATRAE, la Asociación Galega de Profesionais da Tradución e da Interpretación (AGPTI), la Associació Professional de Traductors i Intèrprets de Catalunya (APTIC), la Asociación de Traductores, Correctores e Intérpretes de Lengua Vasca (Euskalitzultzaile, Zuzentzaile eta Interpreteenelkartea lao EIZIE) y La Xarxa - Red de traductores e intérpretes de la Comunitat Valenciana, contactos personales y redes sociales, donde profesionales de la traducción y profesores universitarios de este mismo ámbito dieron visibilidad a la encuesta.

\subsection{Instrumento de recogida de datos}

\subsubsection{Diseño del cuestionario}

Los datos - de naturaleza cuantitativa en su mayoría, aunque se incluyó un reducido número de preguntas que recogen también información de carácter cualitativo - se recabaron mediante un cuestionario en línea diseñado con GoogleForms, el cual nos ofrecía mayor efectividad, inmediatez y facilidad para la recogida y análisis de datos. En cuanto al diseño, este se componía de tres bloques en los que se incluyeron un total de 34 preguntas - divididas en distintos itinerarios dependiendo de la lógica de respuesta de los encuestadosque pretendían recoger los siguientes datos:

- Bloque 1. Perfil socioprofesional del traductor audiovisual desde el francés. Las 16 preguntas de este primer bloque permitían recabar información sobre (1) edad, (2) género, (3) lugar de residencia, (4) años de experiencia como traductor audiovisual, (5) formación académica y (6) formación específica en TAV. En caso afirmativo en la cuestión anterior, se preguntaba (7) la LO en la que se llevó a cabo dicha formación, (8) el tipo de formación, (9) la entidad donde se cursó y (10) las modalidades en las que se centró. Además, se preguntaba a los encuestados si (11) consideraban suficiente la formación recibida en TAV — de haberla tenido-y si (12) consideraban conveniente una mayor oferta formativa en esta modalidad de traducción con francés como LO. Por último, en este bloque se preguntó sobre (13) régimen laboral de los encuestados, (14) lenguas a las que traducen desde el francés, (15) otras posibles combinaciones lingüísticas de trabajo que no incluyeran el francés como LO y (16) si, además de ejercer como traductores audiovisuales, se dedicaban a otra actividad profesional. 
- Bloque 2. Encargos de TAV con francés como LO. Con las 15 preguntas de este bloque se pretendía principalmente recoger información sobre las características de los encargos llevados a cabo por los traductores en los últimos cinco años. Para ello, en primer lugar, se preguntaba si (1) habían recibido algún encargo de TAV con francés como LO durante ese tiempo. En caso negativo, se preguntaba a los encuestados (2) de cuándo databa, aproximadamente, su último encargo desde el francés. A continuación, a aquellos que habían respondido afirmativamente, se les preguntaba sobre (3) el número aproximado de encargos recibidos en ese período de tiempo, (4) impresión — desde la experiencia propia o la de compañeros- sobre un posible aumento del flujo de trabajo desde el francés, (5) lengua meta (LM) traducida con mayor frecuencia, (6) tipo de producto audiovisual traducido en mayor medida, (7) canales de distribución más frecuentes de los productos traducidos, (8) tipo de público al que se solía dirigir el producto, (9) modalidad de TAV más demandada, (10 y 11) modos de facturación en función de la modalidad de TAV, principalmente, doblaje y subtitulación —en el caso de traducir para doblaje, también se pregunta sobre (12) quién era el agente encargado de realizar el ajuste-, (13) principales clientes que solicitaron sus servicios y (14) país de procedencia de dichos clientes. Por último, (15) se preguntó a los encuestados si consideraban sus servicios de TAV desde el francés su principal fuente de ingresos.

- Bloque 3. Cuestiones finales. En este último bloque se formularon tres preguntas abiertas que permitían a los participantes hacernos llegar sus apreciaciones personales — sin restricciones de espacio- acerca de las principales dificultades a las que se enfrentan los traductores audiovisuales que trabajan desde el francés como LO. Asimismo, los encuestados tenían una nueva pregunta donde podían plasmar libremente cualquier otro comentario que desearan. Por último, se les ofrecía la opción voluntaria de facilitar un contacto personal para ser informados de los resultados del estudio.

\subsubsection{Evaluación del cuestionario}

Siguiendo las recomendaciones de Hernández Sampieri et al. (2010), con el fin de afinar y validar nuestro instrumento, sometimos el cuestionario a dos pruebas previas a su difusión: revisión y evaluación por un experto y pilotaje.

La primera versión del cuestionario fue evaluada por un experto referente en el campo de la TAV, el Dr. Juan José Martínez Sierra, quien cuenta con una dilatada experiencia como investigador y docente de TAV, y que también ha dirigido varias tesis doctorales hasta la fecha centradas en esta modalidad de traducción. Las sugerencias del experto para afinar las preguntas de nuestra encuesta se tuvieron en consideración y se modificó la primera versión del cuestionario para recabar información de un modo más eficaz y directo.

Seguidamente, el cuestionario fue pilotado por un total de ocho personas, traductores audiovisuales profesionales en activo, aunque no especializados en lengua francesa; es decir, personas que presentaban un perfil muy similar al de los sujetos de la población, excepto por la LO desde la que ofrecen sus servicios de traducción. En cualquier caso, esto no era relevante para testar el cuestionario, pues el objetivo era comprobar que su estructura resultaba lógica y las preguntas eran claras y fácilmente comprensibles para los traductores. Tras ambas pruebas, se confeccionó la versión final del cuestionario. 


\subsubsection{Difusión y compleción del cuestionario}

Para distribuir el cuestionario entre el mayor número de personas, contactamos con ATRAE, AGPTI, APTIC, EIZIE y la Xarxa, a quienes solicitamos su colaboración para distribuirlo entre sus socios mediante correo electrónico. Asimismo, este también se difundió a través de redes sociales, donde profesionales de la TAV nos ayudaron a dar visibilidad al estudio y obtener un mayor número de respuestas. Tras seis semanas, recogimos un total de 69 respuestas. Esta cifra pareció estancarse a partir de la séptima semana, por lo que decidimos cerrar el cuestionario.

\section{RESULTADOS}

\subsection{Perfil socioprofesional del traductor au- diovisual del francés}

\subsubsection{Datos sociodemográficos}

En primer lugar, en lo que se refiere a la edad de nuestros encuestados, predominan aquellos de entre 31 a 40 años (37,7\%); seguidos de cerca por aquellos de entre 20 a 30 años (36,2\%); en tercer lugar, se sitúan las personas de entre 41 a 50 años (20,3\%); en cuarto, los traductores de entre 51 a 60 años (4,3\%), y, finalmente, aquellos de entre 61 a 70 años $(1,4 \%)$.

Por otro lado, en cuanto al género, una evidente mayoría, el 73,9\%, son mujeres, mientras que los hombres representan solo el $26 \%$. Teniendo presentes estos datos, de ahora en adelante emplearemos el femenino como genérico para referirnos a las personas que participaron en el estudio.

En cuanto al lugar de residencia, el 82,6\% de las encuestadas vive en España, mientras que un $17,4 \%$ lo hace en el extranjero. Las residentes en España provienen de zonas muy dispares: la mayor parte, de Madrid (24,6 \%), la Comunitat Va- lenciana (15,7\%) y Andalucía (14 \%). Con todo, 381 recordemos que estos datos no significan que existan necesariamente mayores oportunidades laborales en estas comunidades autónomas, ya que las traductoras pueden residir en ellas, pero estar trabajando para clientes de diversa procedencia tanto nacional como internacional.

Posteriormente, preguntamos por su grado de experiencia como traductoras audiovisuales. Así, la mayoría contaba con una experiencia de 0 a 5 años $(53,6 \%)$, seguidas por aquellas de 6 a 10 años (24,6 \%); en tercer lugar, de 16 a 20 años (8,7 \%); en cuarto, de 11 a 15 años (7,2 \%); en quinto, de 21 a 25 años (4,3\%), y, por último, de 23 a 30 años (1,4\%).

\subsubsection{Perfil formativo}

La formación de nuestras encuestadas es también de interés para describir su perfil. Por ello, en primer lugar, se les preguntó por sus estudios en términos generales. Las respuestas se pueden ver en el Gráfico 1.

Los datos reflejan que la mayoría (84 \%) ha cursado una carrera universitaria en Traducción e Interpretación (TeI) - o similar-, seguidas por aquellas con una formación en Filología - $\mathrm{O}$ similar- (17,4\%). Por otra parte, hasta un 18,8 $\%$ aseguró haber tenido una formación autodidacta. En realidad, esta era una pregunta de respuesta múltiple, de modo que podía marcarse la opción autodidacta si habían seguido una formación mediante lecturas, cursos congresos o aprendizaje de compañeros, aunque hubieran marcado también la opción de una carrera universitaria. Así pues, de ese $18,8 \%$ — formado por un total de 12 encuestadas-, siete han cursado un grado en TeI, una ha tenido una formación en Filología y otra tiene estudios en Periodismo. Sin embargo, tres de las personas que marcaron esta opción no manifestaron tener una carrera 


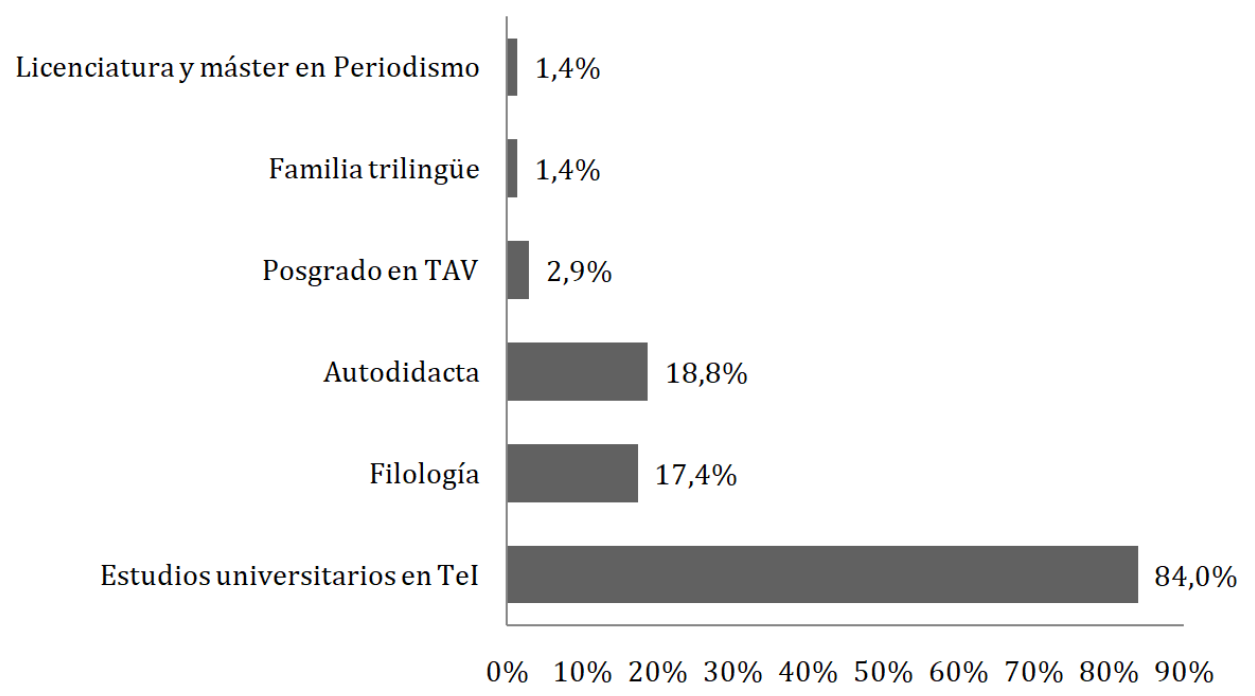

GRÁFICO I. Tipo de formación en general de las 69 encuestadas

universitaria, sino ser únicamente autodidactas. Además, otra de las autodidactas añadió una nueva opción de respuesta: pertenencia a una familia trilingüe, lo que representa el 1,4\%.

Tras esta cuestión, preguntamos a las participantes si contaban con formación específica en TAV. De las 69 encuestadas, $52(75,4 \%)$ afirmaron sí haber cursado formación en TAV, mientras que 17 (24,6\%) negaron tener este tipo de formación. A partir de este punto, aquellas que sí tenían estudios específicos en TAV respondieron a una batería de preguntas adicionales exclusivas para ellas.

Así pues, preguntamos en qué LO se centró la formación a aquellas traductoras que sí cuentan con estudios específicos en TAV. Las respuestas muestran que 48 de las 52 personas $(92,3 \%)$ con formación en TAV siguieron estos estudios con inglés como LO; 30 (57,7\%), con francés; siete $(13,5 \%)$, con alemán, y tres $(5,8 \%)$, con italiano. Asimismo, encontramos una persona con formación también en español como LO y otra, en euskera (1,4\% cada respuesta). De nuevo, esta era una pregunta de respuesta múltiple, de modo que las encuestadas podían haber cursado su formación en TAV en más de una lengua. En este sentido, resulta llamativo, como se puede ver en el Gráfico 2, que la cifra de personas que han tenido formación solo en inglés sea idéntica a la de aquellas que se formaron en francés e inglés. En cambio, un escasísimo número de participantes ha tenido formación exclusivamente en francés.

En tercer lugar, obtuvimos información sobre el tipo de formación en TAV que habían cursado. Los resultados pueden observarse en el Gráfico 3.

El Gráfico 3 muestra cómo una elevada cifra de participantes ha tenido formación en TAV dentro de estudios de máster o posgrado (73,1 \%), seguidos de cursos ofrecidos por asociaciones (42,3\%). Asimismo, la formación en TAV durante el grado o la licenciatura es la tercera opción más frecuente $(30,8 \%)$, por debajo, sin embargo, de los cursos ya mencionados. Por último, 


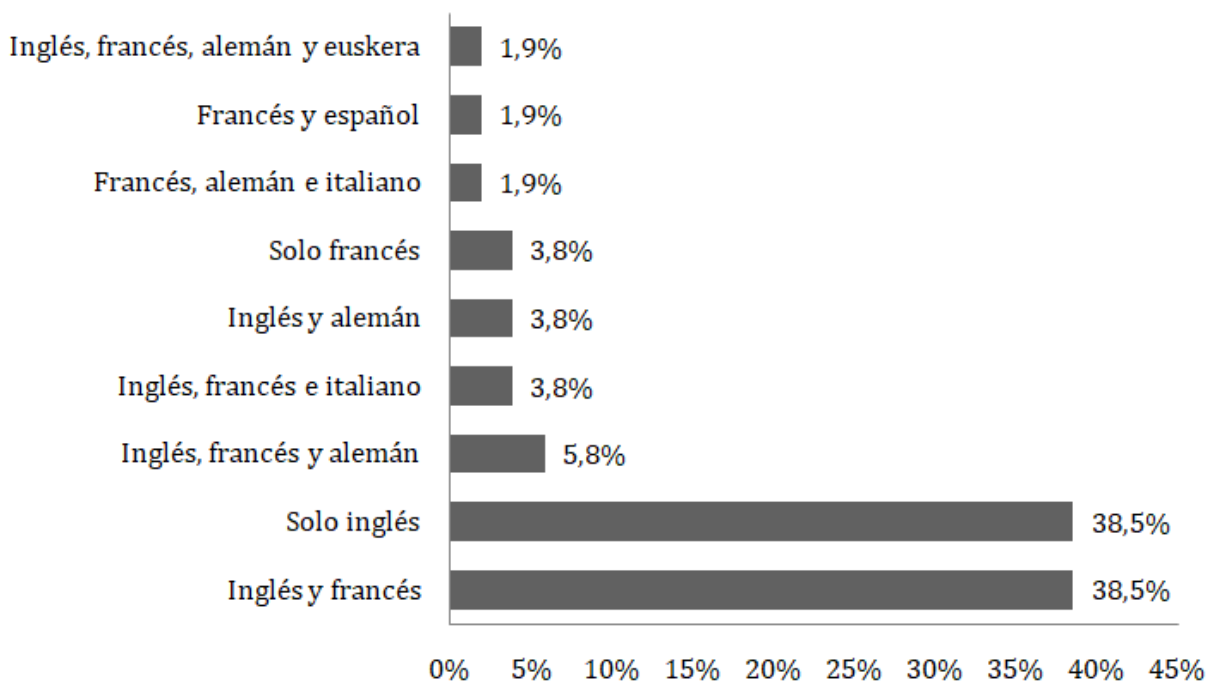

GRÁFICO 2. LO en las que han recibido formación en TAV las participantes

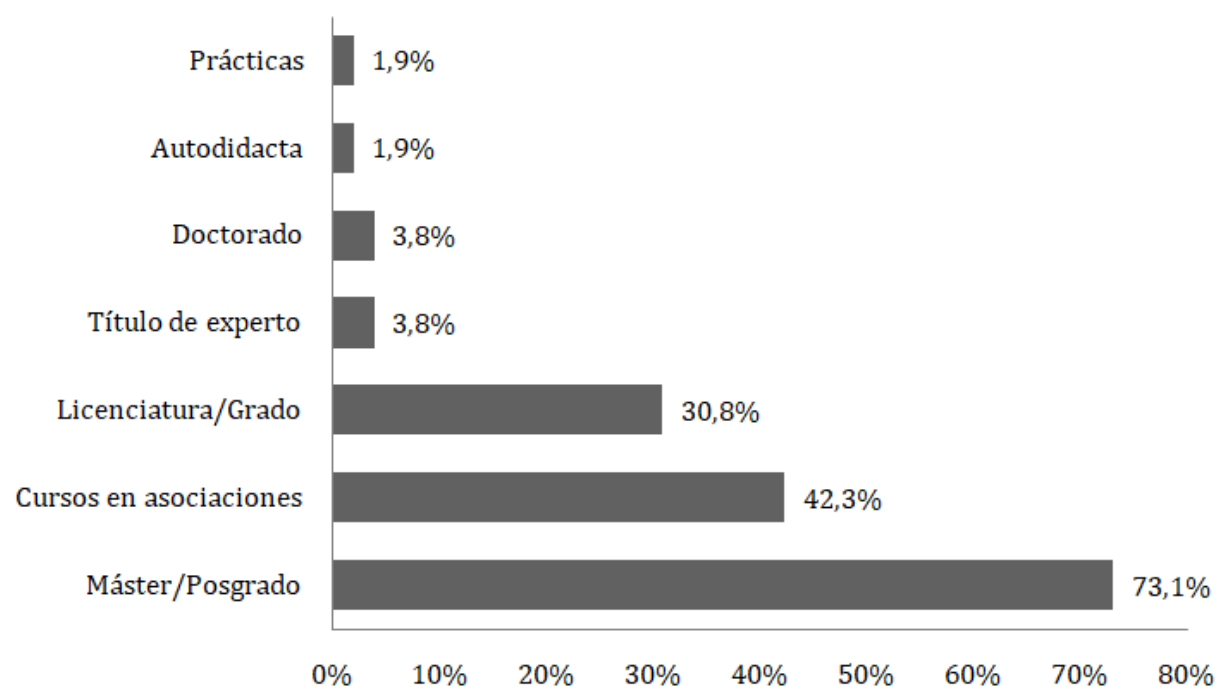

GRÁFICO 3. Tipo de formación en TAV de las 52 encuestadas con estos estudios 
384 un porcentaje menor posee un título de experto o un doctorado ( $3,8 \%$ cada opción). Otras respuestas indican que la formación en TAV se ha adquirido mediante un aprendizaje autodidacta o las prácticas de la carrera (1,9\% cada opción).

Seguidamente, preguntamos en qué entidades (universidades, asociaciones, escuelas profesionales, etc.) habían llevado a cabo esta formación en TAV. Los datos más relevantes apuntan a que, en lo que se refiere a la formación universitaria, la mayor parte estudió en la Universitat Autònoma de Barcelona (28,8\%). Otras universidades mencionadas en mayor medida fueron la Universitat de València $(9,6 \%)$, la Universitat Jaume I y la Universidad de Salamanca (5,8 \% cada una). Por otro lado, en relación con los cursos, los datos muestran que un número ciertamente elevado $(38,5 \%)$ ha seguido esta formación en ATRAE. Asimismo, otras de las entidades en las que se han formado los encuestados más frecuentemente son el Instituto Superior de Estudios Lin- güísticos y de Traducción (ISTRAD) (23,1 \%) o Trágora Formación (13,5\%).

Asimismo, esta formación se centraba en las modalidades de TAV que se muestran en el Gráfico 4 .

Las modalidades más estudiadas son, de lejos, el subtitulado $(98,1 \%)$ y el doblaje $(90,4 \%)$. A estas le siguen las voces superpuestas (57,7 $\%)$ y la accesibilidad audiovisual (53,8 \%). Por otro lado, en el gráfico podemos observar otras opciones de respuesta añadidas por las participantes, si bien el número de personas que respondieron con estas opciones no es excesivamente elevado.

Tras esto, preguntamos a las encuestadas si consideran la formación en TAV recibida suficiente para desempeñar su trabajo sin dificultades. Un 73,1 \% afirmó que sí, mientras que hasta un $26,9 \%$ aseguró lo contrario. Asimismo, preguntamos a las 69 participantes si creían necesaria una mayor oferta formativa en TAV con francés como LO. En este caso, un 78,2 \% de

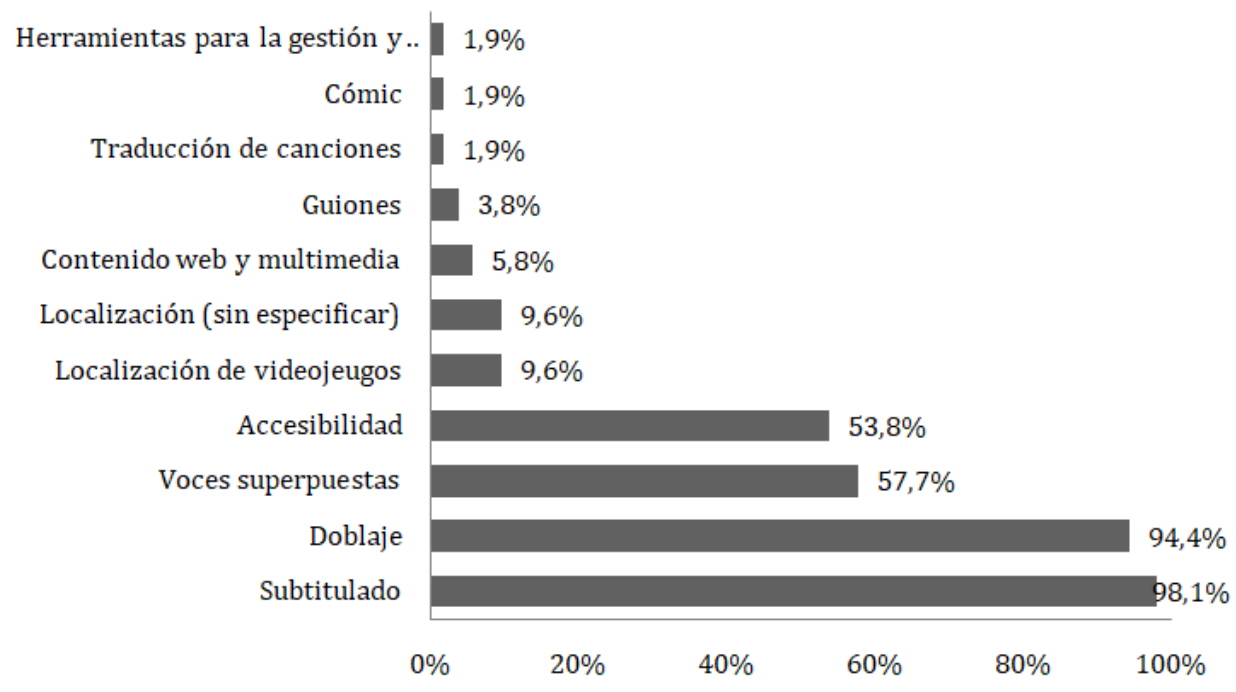

GRÁFICO 4. Modalidades de TAV en las que se centró la formación de las 52 encuestadas 
las traductoras se mostró de acuerdo en que sí, mientras que un $21,7 \%$ respondió lo contrario.

\subsubsection{Situación laboraly servicios ofrecidos}

Para continuar recopilando datos para describir el perfil socioprofesional, en primer lugar, recogimos información acerca de la situación laboral de las participantes. Un 75,4 \% trabaja como profesional por cuenta propia y un $20,3 \%$, por cuenta ajena. Asimismo, encontramos otros perfiles menos frecuentes, como autónomas con empresa propia $(1,4 \%)$, profesora universitaria $(1,4 \%)$ o en búsqueda de empleo $(1,4 \%)$.

Igualmente, preguntamos por sus LM más frecuentes. La mayoría realiza traducciones hacia el español (94,2 \%), seguidas por aquellas que traducen al catalán $(26,1 \%) \mathrm{y}$, por último, al euskera $(10,1 \%)$ y al gallego $(2,9 \%)$. Por otro lado, además de traducir desde el francés, casi la totalidad de las traductoras ofrece servicios en otras combinaciones lingüísticas: inglés-español (82,6 \%), inglés-catalán (18,8\%), italianoespañol y alemán-español (17,4 \% cada opción), español-catalán y catalán-español (10,1 \% cada opción); español-francés (8,7 \%), italiano-catalán o español-inglés (5,8 \% cada opción). Dicho de otro modo, tan solo un 7,2 \% aseguró ofrecer servicios de TAV únicamente desde el francés.

Para cerrar este bloque, preguntamos por la existencia de otra actividad profesional, además de la TAV. Las respuestas pueden observarse en el Gráfico 5.

Solo un 4,3\% asegura no dedicarse a otra actividad profesional que no sea la traducción de productos audiovisuales francófonos. Este porcentaje es visiblemente reducido, por lo que podríamos decir que la mayoría de profesionales especializados en este campo necesitan trabajar en otra actividad o, como ya hemos visto, ofrecer servicios en otras combinaciones lingüísticas que no incluyen el francés como LO.

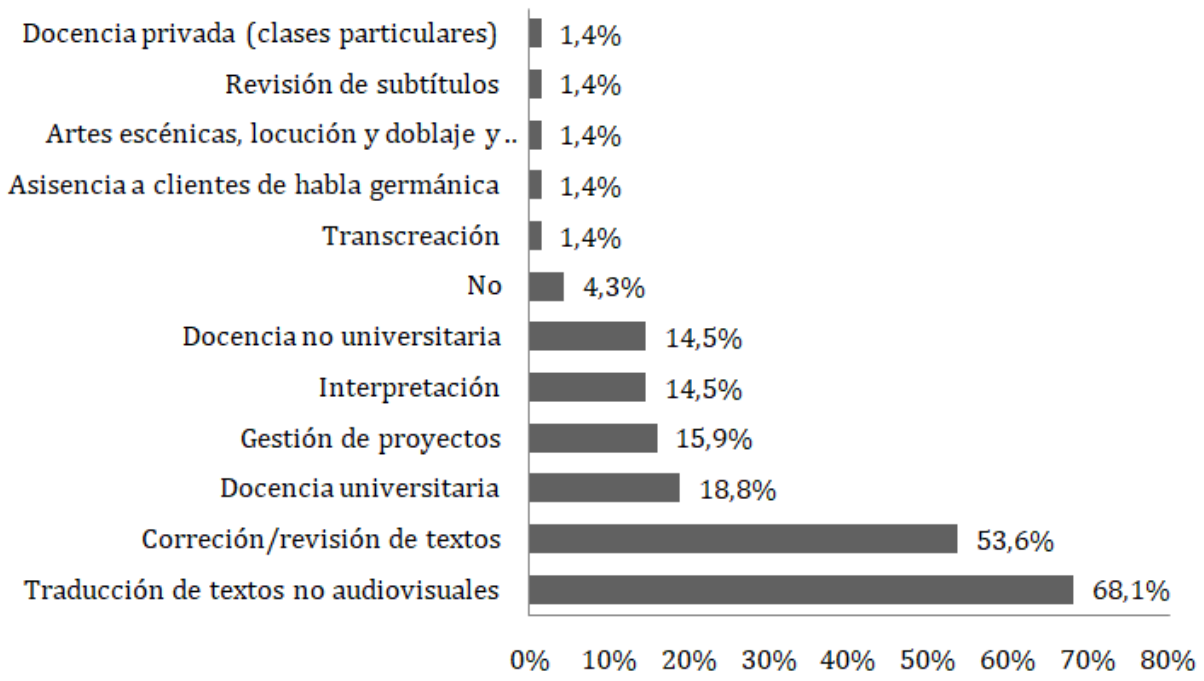

GráFICO 5. Actividades profesionales a las que se dedican las encuestadas además de a la TAV 


\section{4.2. La TAV con francés como LO en los últi- mos cinco años}

En este segundo bloque recogimos datos acerca de las características de los encargos de TAV con francés como LO de los últimos años. Así pues, en primer lugar, para comprobar el flujo de trabajo existente en la traducción de productos francófonos, preguntamos a las encuestadas si habían recibido algún encargo de TAV con francés como LO en los últimos cinco años, a contar desde 2020 . Un 79,7 \% sí había recibido encargos, mientras que un $20,3 \%$, no. A ese $20,3 \%$ preguntamos sobre la fecha de su último encargo de estas características. Un 71,4 \% indicó que hacía más de 10 años, mientras que un 28,6\%, de 6 a 10 años. Vemos, por lo tanto, que pese a ofrecer servicios desde la lengua francesa, hasta 10 traductoras no trabajan con esta lengua desde hace más de 10 años. Por otra parte, preguntamos por un número aproximado de trabajos facturados en ese período de cinco años a aquellas que sí habían tenido encargos recientemente. La mayor parte $(32,7 \%)$ respondió haber recibido de 1 a 5 encargos, seguidas de cerca por quienes habían llevado a cabo más de 35 encargos (21,8 $\%)$. Otros porcentajes fueron: de 11 a 15 encargos $(16,4 \%)$, de 6 a 10 encargos (14,5\%), de 16 a 20 encargos (10,9\%), de 26 a 30 encargos (3,6\%).

Además, nos interesaba comprobar si las participantes habían constatado - a través de su propia experiencia o de terceros - un aumento del flujo de trabajo de productos audiovisuales francófonos en los últimos años. De entre todas las encuestadas, un 45,5\% no cree haber experimentado un aumento de encargos, mientras que un $20 \%$ afirmó lo contrario y un 34,5\% respondió no saberlo y preferir no contestar. Así pues, pese a los datos que recogíamos sobre la industria al comienzo de nuestro artículo, casi la mitad de las traductoras no cree contar con más trabajo actualmente.
Por otra parte, en referencia a la LM, los resultados muestran cómo el español es la más demandada $(87,3 \%)$, seguida del catalán $(14,5 \%)$, el euskera (5,5 \%) y el gallego (1,8 \%). Asimismo, preguntamos por el tipo de producto audiovisual traducido con mayor frecuencia. Las respuestas pueden observarse en el Gráfico 6.

Por otro lado, los resultados sobre los canales de distribución más frecuentes de los productos traducidos se pueden ver en el Gráfico 7.

En cuanto a los principales receptores de los productos traducidos, los resultados apuntan a un público adulto en la mayor parte de casos $(96,4 \%)$, mientras que un porcentaje más reducido de los productos están dirigidos a un público infantil (10,9\%). Asimismo, la modalidad de TAV más frecuentemente demandada puede verse en el Gráfico 8.

Los encargos de subtitulación parecen ser los más demandados (74,5\%), seguidos, de lejos, por los encargos de doblaje (32,7\%) y por la tercera modalidad más demandada, las voces superpuestas (7,3\%). Estos datos pueden resultar de especial interés a las futuras traductoras y formadoras, pues, como vemos, el mayor volumen de trabajo dentro de la TAV desde el francés se concentra en los encargos de subtitulado.

Otra cuestión de interés para acercarnos a la realidad profesional es el modo de facturar los encargos. En el caso de subtitulación, la mayoría (81,4 \%) cobra el encargo por minuto; de lejos, le siguen aquellas que declaran cobrar por subtítulo (14\%), y, por último, otras opciones menos frecuentes, como por palabra (de la transcripción) $(4,6 \%)$ o tarifa mínima o sueldo de trabajador en plantilla (2,3\% cada opción). Por otro lado, en el caso de doblaje, encontramos dos claras tendencias: o bien por minuto, o bien por rollo (10 minutos) (51,6 \% cada opción). Otros modos de facturar menos frecuentes parecen ser por producto - de acuerdo a lo fijado por el precio del estudio-, por palabra, por contrato, o cantidad fija 


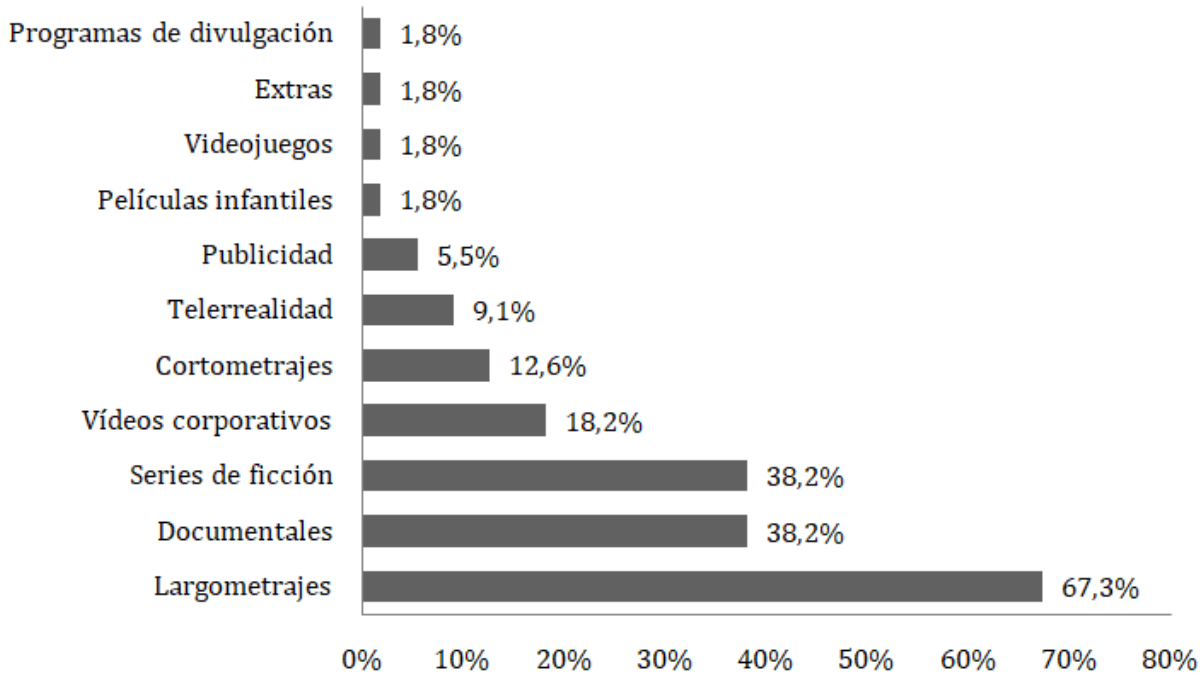

GrÁfICO 6. Producto audiovisual traducido con mayor frecuencia por las encuestadas

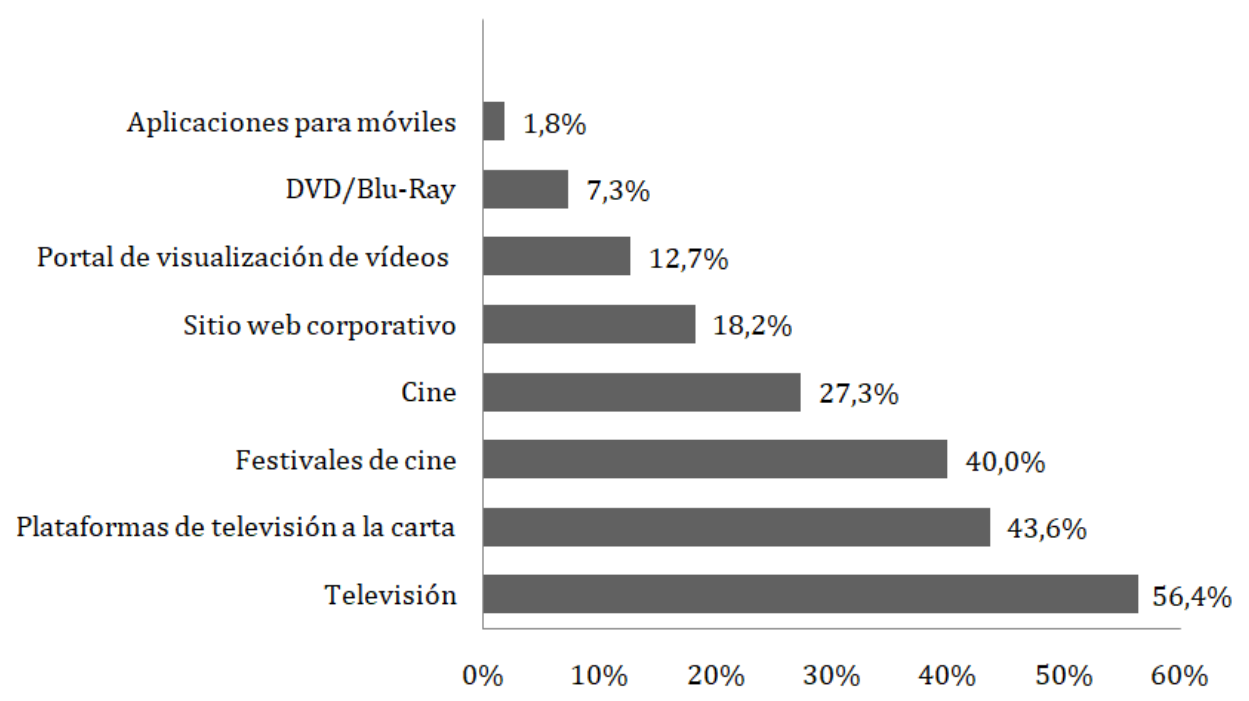

Gráfico 7. Principales canales de distribución de los productos audiovisuales traducidos por las encuestadas 


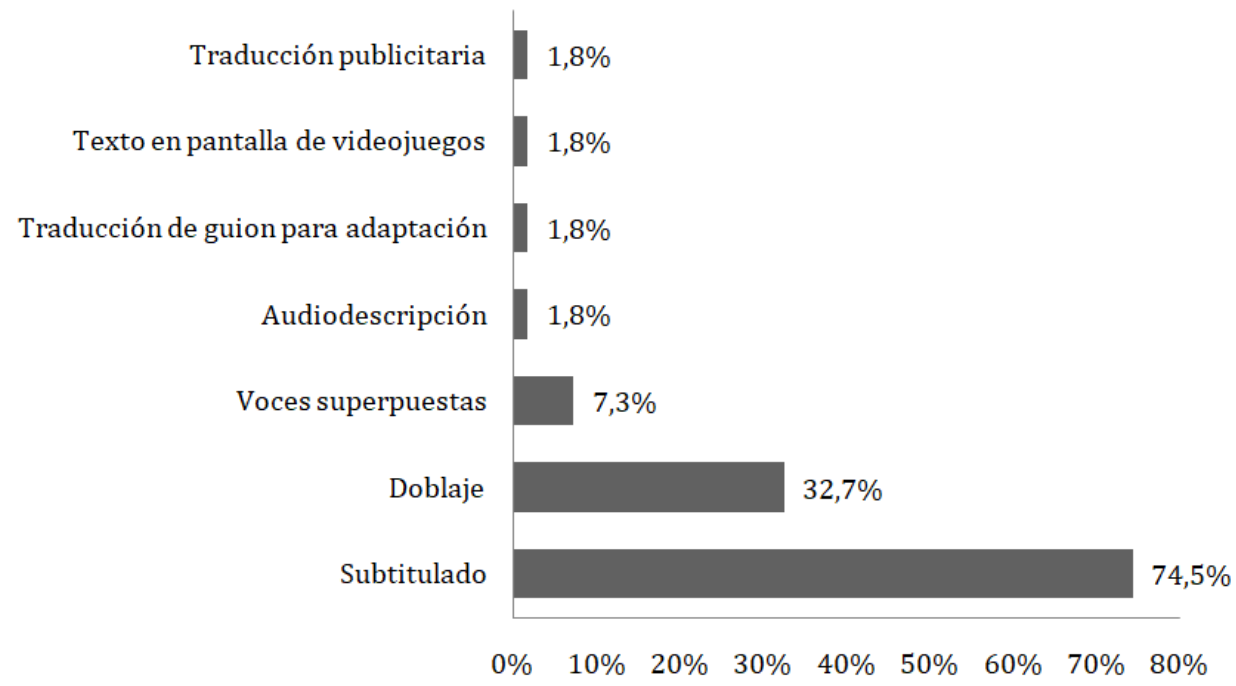

GRÁFICO 8. Modalidades de TAV más traducidas por los encuestados en los últimos cinco años

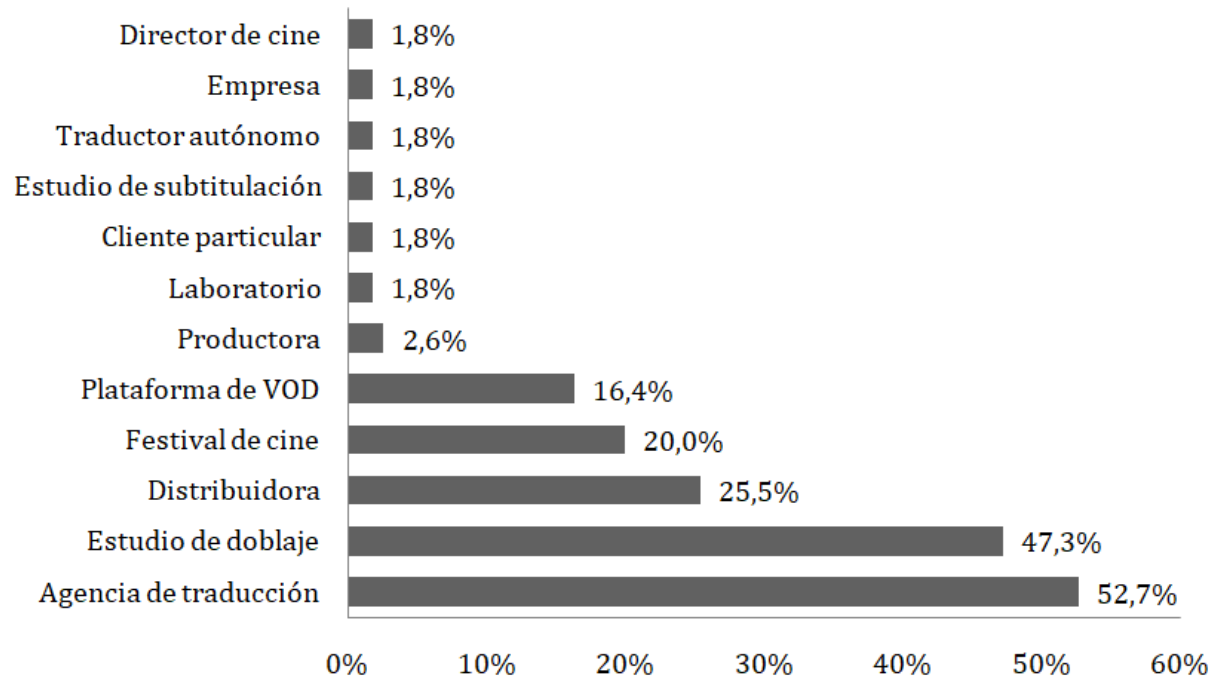

GrÁfICO 9. Principales clientes de las encuestadas 
por proyecto de 25-30 minutos o 45-60 minutos (3,2 \% cada opción).

En lo que se refiere al proceso de doblaje, también nos resultaba de interés comprobar quién suele ser la persona encargada de realizar el ajuste. Los resultados apuntan claramente a que en la mayoría de casos (76,7\%) es un técnico o ajustador, mientras que en muchas menos ocasiones $(36,7 \%)$ es la propia traductora quien ha de hacerlo.

Como últimas cuestiones de este bloque, preguntamos acerca de los principales clientes en los últimos cinco años. Los datos fueron los siguientes: una agencia de traducción (52,7\%), estudios de doblaje (47,3\%), distribuidoras (25,5\%), festivales de cine (20\%) y plataformas de VOD $(16,4 \%)$. Otras opciones señaladas pueden observarse en el Gráfico 9.

En cuanto al origen de esos clientes, los datos revelan que la mayoría (74,5 \%) está situada en España, aunque también encontramos una cifra ciertamente elevada (47,3\%) de clientes extranjeros.

Para concluir, preguntamos a las traductoras si consideraban los encargos de TAV desde el francés su principal fuente de ingresos en los últimos años. Los resultados parecen poco alentadores si tenemos en cuenta que hasta un 92,7 \% respondió que no, mientras que solamente un 7,3 \% afirmó vivir principalmente de esta actividad.

\subsection{Impresiones y comentarios de las traduc- toras}

En el tercer y último bloque recogimos dos preguntas abiertas con la intención de permitir a las encuestadas dejar sus impresiones voluntariamente y sin restricciones de espacio. La primera cuestión preguntaba acerca de los principales retos o dificultades a los que se enfrenta la traductora audiovisual con francés como LO. Los comentarios más repetidos $(46,67 \%)$ fueron, en primer lugar, la falta de producción de obras audiovisuales francófonas en comparación con las de lengua inglesa y, en consecuencia, de flujo de encargos, lo cual repercute, como es lógico, en la estabilidad laboral de las traductoras. En segundo lugar, un número ciertamente elevado (37,78 \%) denunció las bajas tarifas ofrecidas desde el francés como LO - aunque algunas encuestadas aclaran que esto sucede también con otras combinaciones lingüísticas - y el costoso trabajo que supone negociar tarifas dignas. La tercera dificultad más mencionada (20\%) fue la invisibilización que sufre la lengua francesa en el mercado de la TAV, quedando eclipsada por el inglés, el cual se emplea como lengua puente para la traducción de plantillas y guiones (pivot template). Así, algunos productos francófonos parecen traducirse a partir de estas plantillas en inglés, en lugar de ser traducidos desde el francés directamente. Esto puede provocar, de acuerdo con una de las encuestadas, que la calidad de las traducciones sea menor, pues no se precisa de traductoras especialistas en francés - es más, según critica, algunas ni tan solo poseen conceptos básicos de la lengua - para traducir una obra francófona. Cuando esto ocurre, el francés queda relegado a una mera lengua de apoyo gracias a lo que se entiende de oído, en caso de comprender esta lengua. Veamos algunos de los comentarios al respecto:

Encuestada 1: Hay mucha invisibilización del idioma y prácticamente se trabaja, como muchos otros idiomas, con el inglés como lengua puente. Se proporcionan materiales en inglés directamente (p.e. plantilla de subtítulos en EN en lugar del guion original en francés).

Encuestada 2: Las tarifas que ofrecen las empresas de subtitulado francesas en la combinación FR $>$ ES son relativamente bajas a día de hoy. En el caso de las plataformas VOD, casi todas las lenguas originales pasan por una plantilla en inglés (pivot tem- 
390

plate) de la que parten las traducciones a todas las demás lenguas. Es decir, pese a ofrecer una combinación $F R>E S$, a día de hoy, lo más común es que me encarguen traducir contenido original en francés [a] partir de una plantilla en inglés, en vez de directamente FR $>E S$. Sé que hay intención de cambiar esto desde hace un tiempo, pero de momento no he visto que se haya dado ningún paso.

La cuarta dificultad más mencionada (15,55 \%) son los ajustados plazos que se les ofrece para entregar las traducciones, llegando incluso, de acuerdo con una encuestada, a ser más cortos que cuando se traduce desde el inglés. Por último, otras dificultades parecen ser la falta de formación en TAV desde el francés, las malas condiciones en las que llegan las transcripciones o guiones, la falta de competencia lingüística de algunas traductoras al no ser el francés la primera lengua extranjera desde la que traducen, el desigual reparto del trabajo, el desconocimiento por parte de los clientes de que algunas de nuestras participantes también traducen desde el francés, la falta de material adicional para traducir o el intrusismo laboral. Seguidamente, destacamos un comentario de particular interés:

Encuestada 3: Además de traducir del francés (únicamente), reviso el trabajo de otros traductores y veo que el $90 \%$ tiene el francés como segundo idioma y sus traducciones suelen ser mediocres. En cuanto hay matices, no los captan. Calcan mucho las construcciones francesas. Muchos de ellos no aceptan los trabajos si hay que traducir de oído. Intento siempre encargar los trabajos a traductores que tienen como primer idioma el francés, y son pocos. Esto es generacional. También pasa con otros idiomas como el italiano o el alemán. Hay demasiada masificación en inglés.

Para terminar, en la penúltima pregunta - la última se reservó para que dejaran un correo electrónico aquellos participantes que lo desearan-, dejamos un espacio para que las encuestadas nos hicieran llegar libremente cualquier cuestión o impresión que desearan. En ella, encontramos la siguiente declaración que nos gustaría destacar, ya que nos mostramos en consonancia con esta idea: «Me gustaría que se diera más importancia al francés en este sector. Parece que solo existen las películas en versión inglesa».

\section{CONCLUSIONES}

Por una parte, tras observar los datos sobre la industria audiovisual, creemos poder afirmar que la mayor parte del contenido francófono recibido en nuestro país proviene de Francia. No obstante, en su conjunto, no parece que las obras galas constituyan un porcentaje especialmente elevado entre las obras consumidas en España - por ejemplo, el cine francés supuso tan solo un 3,4\% del total del mercado cinematográfico español en el 2019 y el VOD, un 3,5 \%-. Esto conlleva un menor volumen de trabajo para las traductoras formadas en francés debido a la relativamente escasa oferta - sobre todo en comparación con el inglés- de productos audiovisuales en lengua francesa.

Pese a ello, conviene destacar que, por ejemplo, la plataforma TV5Monde Plus — creada con el fin de promover la cultura francófona por el mundo- ofrece en España un elevado número de productos en francés de nacionalidades muy diversas, lo que puede suponer un nicho de trabajo. Asimismo, la implantación de la Directiva UE 2018/1808, que obliga a que el $30 \%$ de los contenidos distribuidos en los países de la UE proceda de Europa, quizá podría traducirse en un aumento del número de obras francófonas distribuidas en España en los próximos años. Hacia esto apunta también Unifrance (2020), que afirma que la apuesta de las plataformas como Amazon, Netflix y de productores locales por contenido galo ha ido en aumento. Sin em- 
bargo, aunque la predominancia del VOD sí se ve reflejada ya en los datos de nuestra encuesta - las participantes marcaron estas plataformas como el segundo canal de distribución de contenidos francófonos $(43,6 \%)$ - todavía no parece haber supuesto un mayor flujo de trabajo, de acuerdo con la percepción de casi la mitad de nuestras encuestadas. Esto se podría explicar, quizás, por la omnipresencia del inglés y su uso como lengua puente para traducir obras francófonas, una práctica un tanto llamativa si tenemos en cuenta que el francés es la quinta lengua más hablada del mundo (OIF, 2019) y figura entre las cinco más traducidas en España (Rico Pérez y García Aragón, 2016). Por ello, teniendo en cuenta los datos, cabría preguntarse si dentro del ámbito audiovisual el francés sería también la segunda lengua más traducida en España, por lo que, para responder a esto, convendría llevar a cabo nuevas investigaciones.

Por otra parte, podemos dibujar el siguiente perfil socioprofesional de las traductoras a partir de los datos de la encuesta. La mayor parte son mujeres jóvenes, de entre 20 a 30 años, cuentan con una experiencia de entre 0 a 5 años, son trabajadoras autónomas y residen, principalmente, en Madrid, la Comunitat Valenciana y Andalucía. La mayoría cuenta con una carrera en TeI, así como con formación específica en TAV. No obstante, aun dedicándose a esta modalidad de traducción, casi el 25 \% no tiene formación en ella. Las modalidades más estudiadas son la subtitulación, el doblaje y las voces superpuestas. Asimismo, casi todas las encuestadas siguieron una formación con inglés como LO; de hecho, solo cuatro personas de 52 no han tenido formación en este idioma. En relación con esto, la mayoría de las participantes considera suficiente su formación para desempeñar su trabajo; sin embargo, cerca del $30 \%$ no lo cree del mismo modo. Aun así, casi el 80 \% se muestra de acuerdo en que es necesaria una mayor oferta 391 formativa en TAV con francés como LO.

La predominancia de la lengua inglesa en lo audiovisual se hace de nuevo evidente al observar cómo el 82,6 \% de las participantes ofrece servicios de traducción desde el inglés además de desde el francés — de hecho, solo el 7,2 \% se dedica a la TAV exclusivamente desde la lengua francesa-. Como cabía esperar, las LM más frecuentes son el español, seguido del catalán, el euskera y el gallego. Finalmente, debemos destacar que tan solo un 4,3\% de las encuestadas se dedica exclusivamente a la TAV de productos francófonos y no tiene otra actividad profesional; en cambio, la mayoría, o bien ofrece servicios en otras combinaciones lingüísticas que no incluyen el francés como LO, o bien se dedica a otra actividad profesional fuera de la TAV: traducción de textos escritos, corrección, docencia, etc. Se hace evidente, por lo tanto, la dificultad de dedicarse con exclusividad a la TAV desde la lengua francesa.

Asimismo, las traductoras denuncian una distribución desigual de los encargos audiovisuales desde el francés, lo cual se ha reflejado en nuestros datos: mientras que un 32,7 \% recibió tan solo de 1 a 5 encargos, un 21,8 \% aseguró haber tenido más de 35 ; es decir, los porcentajes apuntan a un reducido número de encargos en primer lugar y en segundo, al número más elevado que teníamos en las opciones de respuesta. En lo que respecta a las características de estos, la modalidad más demandada es la subtitulación (74,5 \%), un porcentaje muy por encima de la segunda y tercera modalidad: el doblaje $(32,7 \%)$ y las voces superpuestas (7,3 \%). Esto resulta curioso si tenemos en cuenta que España se considera un país principalmente doblador (Chaume, 2004), si bien este hecho ha cambiado durante los últimos años, principalmente, por la aparición del VOD (Agulló García, 
392 2020). Así, este predominio del subtitulado podría obedecer a los canales de distribución más frecuentes de acuerdo con las encuestadas: las plataformas de VOD $(43,6 \%)$ y los festivales de cine $(40 \%)$. Es más, también en la televisión, principal canal de distribución de contenido traducido por las encuestadas $(56,4 \%)$, encontramos el canal TV5Monde - y la plataforma TV5Monde Plus-, cuyos contenidos llegan al público español principalmente subtitulados.

En cuanto a los productos más traducidos, los datos de la encuesta destacan el largometraje $(67,3 \%)$, algo comprensible dado el papel de nuestro país como uno de los máximos importadores de cine galo en los últimos años. Sin embargo, como curiosidad, quisiéramos destacar que, a pesar de que España es el tercer mayor consumidor de cortometrajes franceses (Unifrance, 2020), estos suponen tan solo el 12,6\% de contenido audiovisual traducido por nuestras encuestadas. Así, estos datos podrían resultar de interés de cara a la actualización de posibles propuestas formativas de TAV con el francés como LO, ya que permiten entender las modalidades demandadas en el mercado.

Para finalizar, como futuras cuestiones de investigación, todavía quedan preguntas por responder; por ejemplo: ¿existe un tratamiento preferencial por el doblaje o subtitulado en algunas películas? ¿Influyen factores como el género, el éxito comercial o la reputación del director en la modalidad de TAV escogida para la traducción de una obra? ¿Han sido todas las películas francesas de mayor éxito en Francia dobladas y subtituladas para el mercado español? Aun así, en vista de los datos obtenidos, creemos poder afirmar que la industria y la profesión de la TAV con francés como LO no parece encontrarse en un estado óptimo si tenemos presentes el bajo volumen de encargos, el uso del inglés como lengua puente, el reparto desigual del trabajo, etc. Sin embargo, esto no es óbice para que las encuestadas hayan reclamado una mayor formación en TAV desde la lengua francesa. Por ello, esperamos que este artículo permita, en cierto modo, reflexionar sobre la importancia de visibilizar y valorar en mayor medida la profesión del traductor audiovisual desde el francés — aún más en vistas de que en el futuro la producción de obras francófonas podría aumentar-, algo que hasta la fecha no parece estar ocurriendo.

\section{AGRADECIMIENTOS}

En primer lugar, queremos agradecer al Dr. Juan José Martínez Sierra sus consejos a la hora de realizar este artículo, así como la evaluación de la primera versión del cuestionario. Igualmente, damos las gracias a ATRAE, AGPTI, APTIC, EIZIE y La Xarxa por la ayuda en la difusión del cuestionario entre sus socios, así como la de todos los investigadores y profesionales que lo difundieron por redes sociales. Por último, agradecemos también la colaboración de todos los profesionales que participaron en la encuesta, tanto en el grupo piloto como en la versión final.

\section{REFERENCIAS}

Aguado-Guadalupe, Guadalupe e Itziar Bernaola (2019): «El nuevo marco regulador europeo de los servicios audiovisuales bajo petición y de intercambio de vídeo. Su repercusión en el mercado español de plataformas». index.comunicación, 9/3, 13-34. <https://journals.sfu.ca/indexcomunicacion/index.php/indexcomunicacion/article/ view/481/731>. [consulta: 27-II-2021].

Agulló García, Belén (2020): «El paradigma actual de la subtitulación: cambios en la distribución de contenido, nuevos hábitos de consumo y avances tecnológicos». La linterna del traductor, 20, 53-62. <http://www.lalinternadeltraductor.org/ pdf/lalinterna_n20.pdf>. [consulta: 3-III-2021]. 
Bigot, Yves (2020): «Editorial». En s.a., TV5Monde Plus. La plataforma francófona mundial. <https://presse.tv5monde.com/download?n=DP\%20TV5MONDEplus \%20espagnol-pdf\&id=21701>. [consulta: 3-III-2021].

CANADIAN MEDIA PRODUCERS ASSOCIATION DEPARTMENT OF CANADIAN HERITAGE, TELEFILM CANADA, ASSOCIATION QUÉBÉCOISE DE LA PRODUCTION MÉDIATIQUE, NORDICITY (2020): Profile 2019. Economic Report On The Screen-Based Media Production Industry In Canada. <https:// cmpa.ca/wp-content/uploads/2020/04/CMPA _2019_E_FINAL.pdf>. [consulta: 27-II-2021].

Carrero Martín, José Fernando, Beatriz Cerezo Merchán, Juan José Martínez Sierra, y Gora Zaragoza NinET (2019): «Apuntes sobre la situación de la traducción audiovisual en la academia, la docencia y la industria». En José Fernando Carrero Martín; Beatriz Cerezo Merchán; Juan José Martínez Sierra y Gora Zaragoza Ninet (eds.), La Traducción Audiovisual. Aproximaciones desde la Academia y la Industria, Granada: Editorial Comares, 1-4.

Chaume, Frederic (2004): Cine y traducción. Madrid: Cátedra.

De Rosa, Maria y Marilyn Burguess (2017): Exporting Canadian Feautre Films in Global Markets. Trends, Opportunities and Future Directions.

Grece, Christian y Marta Jiménez Pumares (2020): Film and TV content in VOD catalogues. Estrasburgo: Observatorio Audiovisual Europeo. <https:// rm.coe.int/film-and-tv-content-in-vod-catalogues-2020-edition-final/1680a13537>. [consulta: 3-III-2021].

F.M.B. (2012): «TV5Monde subtitula toda su programación al español», $A B C, 18$ de noviembre, $<$ https://www.abc.es/play/television/abci-mondesubtitulos-espanol-201211170000_noticia.html>.

Hernández SAmpieri, Roberto, Carlos Fernández CoLlADO y Pilar BAPTISTA LuCIO (2010): Metodología de la investigación (5a ed.). México D. F.: McGraw-Hill. Ministerio de Cultura y Deporte (2020): Nota resumen. Estadística de Cinematografía: Producción, Exhibición, Distribución y Fomento 2019. <http:// www.culturaydeporte.gob.es/dam/jcr:4060b6e94fa9-4f18-923f-f15066dcc03c/ estadistica-de-cinematografia-produccion-exhibicion-distribucion-yfomento.pdf>. [consulta: 5-III-2021].
Monje Álvarez, Carlos Arturo (2011): Metodología de la investigación cuantitativa y cualitativa. Guía didáctica. Neiva, Colombia: Universidad Surcolombiana.

ObServatorio Audiovisual Europeo (s.f.): Lumiere $V O D<$ http://lumierevod.obs.coe.int/>. [consulta: 3-III-2021].

Observatorio Audiovisual Europeo (2020): Yearbook 2019/2020. Television, Cinema, Video And OnDemand Audiovisual Services - The Pan-European Picture. Estrasburgo: Observatorio Audiovisual Europeo. <https://rm.coe.int/yearbook-keytrends2019-2020-en/16809ce58d>. [consulta: 12-III-2021].

ORGANIZACIÓN INTERNACIONAL DE LA FRANCOFONÍA (2019): La langue française dans le monde. Édition 2019. París: Éditions Gallimard. <https://www. auf.org/wp-content/uploads/2019/04/languefranc\%CC\%A7aise-dans-le-monde-2019.pdf>. [consulta: 12-III-2021].

Reverter Oliver, Beatriz, Juan José Martínez Sierra, Diana González Pastor y José Fernando Carrero Martín (2020): «Modalidades de traducción audiovisual. De clasificaciones y nuevas tendencias», en Beatriz Reverter Oliver, Juan José Martínez Sierra, Diana GonzÁlez PASTOR y José Fernando Carrero Martín (eds.). Modalidades de traducción audiovisual. Completando el espectro, Granada: Editorial Comares, XI-XVI.

Rico PÉREz, Celia y Álvaro García Aragón (2016): Análisis del sector de la traducción en España (2014-2015). Campus de Villaviciosa de Odón: Universidad Europea de Madrid. <https://abacus.universidadeuropea.es/handle/11268/5057>. [consulta: 11-III-2021].

S.A. (2012): TV5Monde. La mejor de la televisión en francés con subtítulos en español. Dossier de prensa. <http://www.tv5monde.com/cms/userdata /c_bloc_file/6/6393/6393_fichier_Dossier-de-Presse-FINAL.pdf>. [consulta: 11-III-2021].

S.A. (2020): TV5Monde Plus. La plataforma francófona mundial. <https://presse.tv5monde.com/ download?n=DP\%20TV5MONDEplus\%20espagnolpdf\&id=21701>. [consulta: $11-$ III-2021].

TV5Monde Europe (2019): About TV5Monde. <https:// europe.tv5monde.com/en/about/about-tv5monde-99086>. [consulta: 11-III-2021].

UNIFRANCE (2020): Les films français à l'international. Résultats salles / Sélections festivals / Exporta- 
394 tion courts-métrages / Exportation VR. <https: //medias.unifrance.org/medias/103/121/227687/ piece_jointe/informe-sobre-los-resultados-delcine-frances-en-el-extranjero-en-el-2019.pdf >. [consulta: 10-III-2021].

UNIÓN EUROPEA (2018): DIRECTIVA (UE) 2018/1808 DEL PARLAMENTO EUROPEO Y DEL CONSEJO de 14 de noviembre de 2018 por la que se modifica la Directiva 2010/13/UE sobre la coordinación de determinadas disposiciones legales, reglamentarias y administrativas de los Estados miembros relativas a la prestación de servicios de comunicación audiovisual (Directiva de servicios de comunicación audiovisual), habida cuenta de la evolución de las realidades del mercado. <https://eur-lex.europa.eu/legal-content/ES/TXT/?uri=CELEX:32018L1808>. [consulta: 9-III-2021]. 